\title{
Thick-film Heavy-metal Sensor of Chalcogenide Glass
}

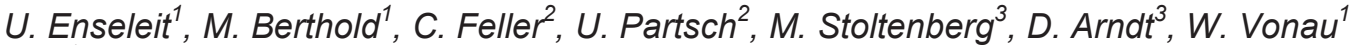 \\ ${ }^{1}$ Kurt-Schwabe-Institut für Mess- und Sensortechnik e.V. Meinsberg, Waldheim, \\ ${ }^{2}$ Fraunhofer Institut für Keramische Technologien und Systeme, Dresden, \\ ${ }^{3}$ PRIGNITZ Mikrosystemtechnik GmbH, Wittenberge \\ enseleit@ksi-meinsberg.de
}

\begin{abstract}
:
This paper reports on the development and verification of a potentiometric sensor based on chalcogenide glass of novel composition to determine copper ions in aqueous solutions. The sensor is assembled by way of thick-film technology on a ceramic substrate.
\end{abstract}

Key words: Heavy metal ion sensor, determination of heavy metals, potentiometric sensor, chalcogenide glass, thick-film technology, copper, lead.

\section{Introduction}

Sensors and the measuring technology in its context are indispensable for our present-day life. Heavy metals may get into the environment via industrial waste water and exhaust gases, for example, and may harm humans and the environment due to their toxic properties. Hence, there is an urgent need for heavy-metal detection in environmental analytics as well as for the surveillance of industrial processes. Especially in water analysis, ion selective electrodes (ISE) have stood the test, as they are reasonable in price, simple to handle and capable of being used in "on-site" analytics [1].

\section{Investigations}

One focus of the work consists in developing and verifying novel ion-sensitive chalcogenide glass in a tube furnace [2,3] and in characterizing it by way of scanning electron microscopy (REM-EDX), X-ray diffractometry $(X R D)$, differential thermal analysis (DTA), thermogravimetry (TGA), dilatometry and atomic absorption spectroscopy (AAS) to qualitatively and quantitatively determine the composition of the amorphous materials (Fig. 1).

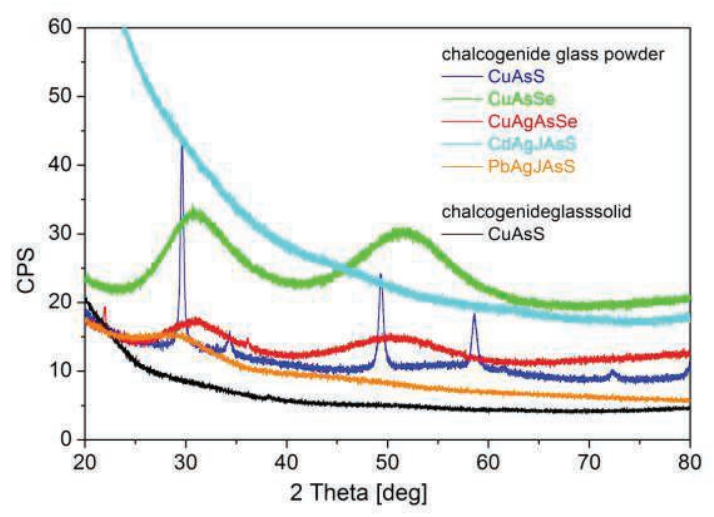

Fig. 1. X-ray diffraction diagrams of $\mathrm{Cu}^{2+}$ and $\mathrm{Pb}^{2+}$ sensitive solid chalcogenide glass.

Preliminarily, rod-like potentiometric chalcogenide-glass sensors were manufactured, followed by assembling thick-film electrodes by applying glass paste onto a planar ceramic substrate in order to test their electrochemical properties regarding their electrode functionality (Fig. 2), transverse sensibility, response behavior and long-term stability. 


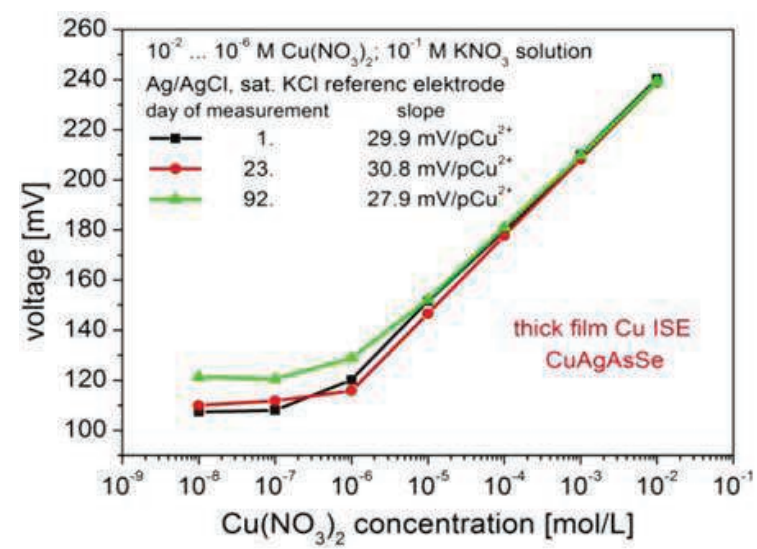

Fig. 2. Calibration curve of a copper electrode in thick-film technology

\section{Sensors}

The sensor layout of a multisensor manufactured in thick-film technology to determine the $\mathrm{pH}$ value, the redox potential, the temperature and the $\mathrm{Cu}^{2+}$-ion concentration is shown in the microscopic image of Figure 3 in fourfold enlargement. The multisensor is $15 \mathrm{~mm}$ long and $6 \mathrm{~mm}$ wide. On the underside, there is a $\mathrm{Ag} / \mathrm{AgCl}$ reference electrode and a Pt1000 temperature-measuring sensor.

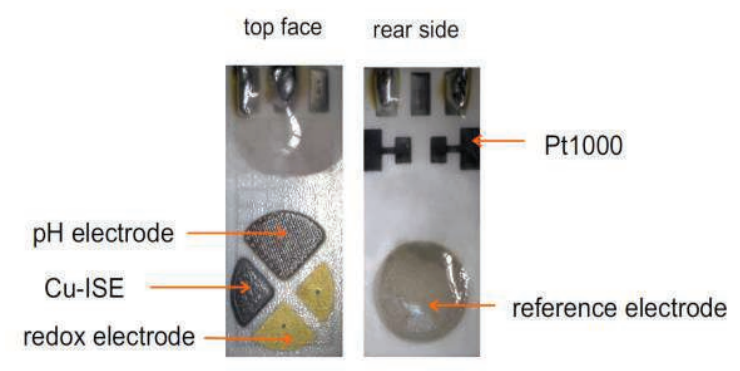

Fig. 3: Multisensor (enlarged fourfold)

\section{Summary}

Novel ion-sensitive chalcogenide glass was smelted and characterized for manufacturing a reasonably priced, mechanically robust and miniaturized thick-film-based $\mathrm{Cu}^{2+}$-heavy-metal ion sensor and, after assembly, tested by rodlike and thick-film measuring electrodes.

In addition to that, multisensors were produced. The sensor arrays can be used to determine the $\mathrm{pH}$ value, the redox potential, the temperature and the copper-ion concentration in solutions.

\section{References}

J. P. Kloock, Herstellung und Charakterisierung von Sensormembranen aus Chalkogenidglasschichten für den Einsatz als Schwermetallsensor in Flüssigkeiten, TU IImenau Universitätsbibliothek, Auflage 1, 2009, mv-Verlag, ISBN: 978-3-939473-43-5.

Y. G. Vlasov, E. A. Bychkov, A. M. Medvedev, Copper ion-selective chalcogenide glass electrodes, Analytical characteristics and sensing mechanism, Analytica Chimica Acta, Vol. 185, 1986, pp. 137-158.

U. Enseleit, M. Berthold, C. Feller, U. Partsch, S. Körner, W. Vonau, Chalcogenide Glass Based Heavy Metal Sensors, Sensors \& Transducers, Vol. 219 (1), 2018, pp. 1-8.

\section{Acknowledgements}

The financial support by the German Federal Ministry of Economics and Technology in the context of the AiF project (grant number KF2218321KM4) is acknowledged. 